\title{
SABERES INDÍGENAS E RESSIGNIFICAÇÃO NO PROCESSO IDENTITÁRIO DOS SATERÉ-MAWÉ/AM
}

\author{
RENAN ALBUQUERQUE RODRIGUES ${ }^{1}$
}

$U F A M$

ALUÍZIO DA SILVA RIBEIRO NETO

UFAM

MARIA DE LOURDES FERREIRA DA SILVA ${ }^{3}$

UFAM

\begin{abstract}
RESUMO: $O$ trabalho discute saberes tradicionais e seu papel na produção da identidade étnica, tendo como referência o povo Sateré-Mawé. A metodologia empregada foi a pesquisa bibliográfica em produções que abordam a temática implicada em identidade cultural $e$ cosmologia sateré-mawé. $O$ saber tradicional, também denominado etnoconhecimento ou saber local, diz respeito a conjuntos de conhecimentos construídos e reconstruídos no seio de dada população tradicional. Na etnia Sateré-Mawé, esses conhecimentos passam por processos de ressignificação, operando na reconstrução da identidade do grupo indígena.
\end{abstract}

PALAVRAS-CHAVE: saberes tradicionais; identidade; Sateré-Mawé.

ABSTRACT: This study discusses traditional knowledge and its role in the production of the ethnic identity, using as reference the Sateré-Mawe indigenous people. The used methodology was bibliographical research of works that approach the themes of cultural identity and cosmology of the Sateré-Mawé. The traditional knowledge, also denominated ethnoknowledge or local knowledge, concerns the body of knowledge built and rebuilt inside a given traditional population. To the Sateré-Mawé ethnic group this body of knowledge goes through a process of

\footnotetext{
${ }^{I}$ Professor Permanente do Programa de Pós-Graduação em Sociedade e Cultura na Amazônia (PPGSCA) da Universidade Federal do Amazonas (Ufam) e lidera o Núcleo de Estudos e Pesquisas em Ambientes Amazônicos (Nepam/CNPq). Possui graduação em Comunicação pela UniNilton Lins/AM (2001), mestrado em Psicologia pela Universidade Federal da Paraíba (2008) e doutorado em Sociedade e Cultura na Amazônia pela Universidade Federal do Amazonas (2013). E-mail: renanalbuquerque @ hotmail.com .

${ }^{2}$ Bacharel em Administração de Empresas pela Universidade Federal do Amazonas (2008), especialista em Turismo e Desenvolvimento Local pela Universidade do Estado do Amazonas (2011) e mestrando em Sociedade e Cultura na Amazônia pela Ufam. É administrador credenciado pelo CRA/AM - Conselho Regional de Administração sob o n ${ }^{\circ}$ 1-6269 e Professor do Curso Superior de Tecnologia em Gestão Pública/UEA. E-mail: admaluizioneto@gmail.com .

${ }^{3}$ Bacharel em Serviço Social pela Universidade Federal do Amazonas (2011) e mestranda do Programa de Pós-graduação Sociedade e Cultura na Amazônia da Ufam. Exerceu a função de Professora Substituta do Curso de Serviço Social do Instituto de Ciências Sociais, Educação e Zootecnia (ICSEZ) da Ufam de 2012 a 2014. Tem experiência na área de Serviço Social, com ênfase em Questão Indígena, atuando principalmente nos seguintes temas: Amazônia, Educação e Educação Inclusiva. E-mail: malusilferreira@gmail.com.
}

Espaço Ameríndio, Porto Alegre, v. 8, n. 2, p. 206-229, jul./dez. 2014. 
RODRIGUES, RIBEIRO NETO e FERREIRA DA SILVA-Saberes indígenas e ressignificação...

resignification process that operates in the construction of the identity of that indigenous group.

KEYWORDS: traditional knowledge; identity; Sateré-Mawé.

\section{Introdução}

Discussões sobre saberes tradicionais são pauta em produções bibliográficas contemporâneas, sobretudo no que se refere ao uso desses saberes por povos não tradicionais (OLIVEIRA, 2013; CARNEIRO DA CUNHA, 2012). Entre as discussões, situa-se o conceito de tradição cultural. A categoria almeja considerar transformações de saberes e fazeres como parte do processo de incorporação de experiências de grupos.

A tradição cultural tende a ser caracterizada em razão da socialidade humana. Por meio de relações sociais se pretende observála na medida em que são atualizadas nesse trâmite interpessoal crenças e ideologias coletivas (VIVEIROS DE CASTRO, 2002). No cerne do suposto, elementos materiais e imateriais configuram o manejo da cultura relacional de grupos amazônicos e populações tradicionais são reconhecidas por características peculiares, tais como transmissão oral da história, uso da terra, relação com a natureza, crenças e sistema de produção (ARGUELLO, 2001).

A tradição cultural se apresenta enquanto expressão da vida, construindo-se e desconstruindo-se a partir de relações reposicionadas e novos limites para novas relações (VIVEIROS DE CASTRO, 2002). A ideia de tradição cultural remete de igual modo à concepção de sistemas em articulação, com partes imbricadas entre si, cuja lógica funciona para entendimentos do eu e do outro (COHN, 2001).

Nesses sistemas estão integrados arcabouços com traços que marcam modos de vida, estabelecendo fronteiras entre etnias (CARNEIRO DA CUNHA, 2012). Esses modos de vida são justamente caracterizados por histórias narradas dos povos, pelo modo oral como eles lidam com contingências, defrontam-se e reconstroem-se (SAHLINS, 1997a e 1997b). 
RODRIGUES, RIBEIRO NETO e FERREIRA DA SILVA-Saberes indígenas e ressignificação...

No trabalho, foi intenção ponderar sobre ressignificações no processo identitário, partindo-se de inferências em relação à população étnica sateré-mawé, da Terra Indígena Andirá-Marau, na divisa entre os Estados do Amazonas e Pará, Amazônia Brasileira. O estudo objetivou explorar o papel de saberes tradicionais na produção da identidade dos índios.

\section{Marco teórico}

\subsection{Saberes tradicionais em populações indígenas}

O modo de vida da maioria das populações nativas amazônicas resulta do conhecimento transmitido de geração a geração segundo tradições culturais, estejam estas no plano subjetivo ou objetivo (VIVEIROS DE CASTRO, 2007). Em sociedades ameríndias, formas de comportamento, trabalho ou crença são produto humano construído e reconstruído dentro de processos socio-históricos, que moldam justamente a ideia de tradição cultural. A perspectiva se relaciona com conhecimentos que representam o ethos de dada população tradicional, a identidade do fazer-se.

A concepção contemporânea em torno do conceito da tradição cultural aponta para cernes relacionados a sistemas de significados que envolvem crenças, atitudes, valores e ideologias, margeando regras, sinais, símbolos e costumes, os quais exercem influência sobre determinada sociedade, seja ocidental ou indígena, tradicional ou não tradicional (SILVA, 2011).

A tradição cultural se remete, ainda, ao não esgotamento da existência como fonte de vida. Agir contra o esgotamento é tornar-se apto às mudanças físicas e mentais, direcionando-se rumo ao engajamento dentro de hábitos e costumes tradicionais. A tradição cultural tende a ser concebida como molde que organiza maneiras de pensar e orientar valores e comportamentos no meio social.

A tradição cultural, ao considerar a reconstituição de identidades diferenciadas, pode ser entendida como construção humana e enquanto tal determina o ser e seus saberes. Ao estar em construção, firma-se 
RODRIGUES, RIBEIRO NETO e FERREIRA DA SILVA-Saberes indígenas e ressignificação...

como trabalho em progresso e consolida padrões que passam a reger pessoas e ambientes circundantes (COHN, 2001).

A tradição cultural fortalece a perpetuação de conhecimentos tradicionais. Essa forma de conhecimento tem sido difundida em várias instituições de pesquisa e financiamento - no Banco Mundial, na Organização Mundial da Saúde (OMS), na Organização das Nações Unidas para a agricultura e alimentação, na Organização Mundial de Propriedade Intelectual, na Organização das Nações Unidas para Educação, Ciência e Cultura (Unesco) e também em outros círculos menos oficiais (CARNEIRO DA CUNHA, 2012).

$O$ estudo se insere na perspectiva, portanto, de explorar o papel do conhecimento pertencente às populações tradicionais em razão de saberes construídos no seio das populações como fruto de sistemas de tradição cultural. Foi meta enfatizar o que diz respeito a formas peculiares de conhecimento, não estáticas e legitimadoras de identidade (FREITAS PINTO, 2011).

No percurso, importou considerar que saberes tradicionais se constituem enquanto conhecimento imanente, dado se apresentarem como elementos constitutivos da identidade de população ancestrais, aglutinando expertises sobre natureza e cultura via marcadores étnicos. Diegues e Pereira concebem populações tradicionais como

[...] povos e comunidades tradicionais: grupos culturalmente diferenciados e que se reconhecem como tais, que possuem formas próprias de organização social, que ocupam e usam territórios e recursos naturais como condição para sua reprodução cultural, social, religiosa, ancestral e econômica, utilizando conhecimentos, inovações e práticas gerados e transmitidos pela tradição (DIEGUES e PEREIRA, 2010, p. 39).

Assim, foi possível caracterizar a população tradicional em tela pelo modo de vida, dando abrangência à transmissão de conhecimentos via narrativas, à relação que pessoas estabelecem com territórios, à produção de alimentos para subsistência e ao caráter econômico précapitalista (CARNEIRO DA CUNHA, 2012; DIEGUES, 2008; OLIVEIRA, 2013). 
RODRIGUES, RIBEIRO NETO e FERREIRA DA SILVA-Saberes indígenas e ressignificação...

\subsection{Relação pessoa-ambiente}

Para Diegues,

na concepção mítica das sociedades tradicionais existe simbiose entre o homem e a natureza [...] onde o tempo para pescar, caçar e plantar é marcado por mitos, pelo aparecimento de constelações estelares, por proibições e interdições (DIEGUES, 2008, p. 63).

Portanto, o saber pertencente a essas populações constitui-se enquanto tradição cultural. Uma tradição em devir, permeadora de relações entre populações e sociedade, em processos de ruptura e continuidade com elementos em ressignificação, influenciando a identidade dos sujeitos para além da simples necessidade de estar no mundo (SANTANA, 2009).

A percepção das dinâmicas sociais e culturais exige que se atente não apenas às tradições, como também à inovação; não se nega, assim, a reprodução social, mas amplia-se a noção de reprodução social, de modo que inclua a possibilidade de mudança. Desse modo, vai-se além da proposição de que estas sociedades têm, em todos os seus aspectos, o objetivo único da perpetuação estanque (COHN, 2001, p. 37-38).

Assumindo o descrito, tem-se que transformações vivenciadas em sociedade são sinalizações propícias a se perceber a própria tradição cultural como processos inerentes a saberes constituídos. São atos materializados via representação de elementos moldados na medida em que indivíduos os experimentam, criam e recriam, buscando reconfigurar existências.

De modo que saberes que norteiam modos de vida de povos tradicionais amazônicos estão relacionados a formas de trabalho e organização política, por exemplo. Investigar nesse caminho tende a ser indicativo para se expressar saberes da tradição ${ }^{4}$, uma vez que se objetiva neste artigo descrever marcadores étnicos que caracterizam a

\footnotetext{
${ }^{4}$ Expressão utilizada por Santana (2009) para conceituar saberes da tradição como um conjunto de conhecimentos sujeitos a transformações que emergem das dinâmicas históricas e das mudanças que se operam na cultura.
}

Espaço Ameríndio, Porto Alegre, v. 8, n. 2, p. 206-229, jul./dez. 2014. 
RODRIGUES, RIBEIRO NETO e FERREIRA DA SILVA-Saberes indígenas e ressignificação...

etnia Sateré-Mawé e a influência deles na construção da identidade do povo.

Um exemplo de saberes da tradição são os ateliês de arquitetura na aldeia de São Pedro, alto rio Tiquié, fonte de pesquisa de Oliveira (2007), nas malocas indígenas do alto Rio Negro. O artesanato criado pelos indígenas dessas malocas possui configuração que impulsiona a observação de profissionais de várias áreas, como matemáticos, antropólogos, geólogos, geógrafos e artesãos miniaturistas. Os objetos apresentam medidas geométricas lapidadas com escalas e proporcionalidades.

Mas até que ponto a tradição cultural se insere a partir desses ateliês, já que são apenas comunidades tradicionais? Por que pouco são demandadas valorizações necessárias à distribuição de dividendos, participação nos lucros ou recursos e criação de políticas públicas comunitárias aos tradicionais em função dessa tradição? São duas questões exemplificadoras dos desafios para os quais as tradições culturais apontam, no sentido de se refletir sobre saberes simetrizados em face ao cotidiano ocidental, que cada vez mais troca relações mediadas por imediatismos.

\section{Material e métodos}

Realizou-se levantamento bibliográfico acerca de saberes locais e científicos na Amazônia, levando-se em consideração quatro categorias teóricas: i) Saberes Tradicionais; ii) Etnia Sateré-Mawé; iii) Xamanismo e iv) Identidade Cultural. Segmentou-se o levantamento para a região do Baixo Amazonas, no extremo do Estado do Amazonas com o Pará.

Nessa área, está situada a Terra Indígena Andirá-Marau, a mais extensa faixa hidroflorestal do leste do Estado do Amazonas e com mais alta biodiversidade da mesorregião fronteiriça indicada.

Foram selecionados autores por categoria, a fim de verificar dois eixos de discussão voltados para o propósito do artigo: "O papel dos saberes tradicionais na cosmologia sateré-mawé" e "A identidade sateré-mawé frente a ressignificações dos saberes da tradição".

Interpretações relacionadas a leituras de textos que abarcassem 
RODRIGUES, RIBEIRO NETO e FERREIRA DA SILVA-Saberes indígenas e ressignificação...

temáticas condizentes ao estipulado se deram a partir desses eixos, e buscou-se orientar inferências em razão de pressupostos que seguissem padrões comportamentais descritos.

Foram efetivadas ponderações sobre sistemas de parentesco, matrizes familiares, memorialismos e espiritualidade.

\section{Resultados e discussão}

\subsection{O papel dos saberes da tradição na cosmologia sateré-mawé}

Os Sateré-Mawé integram o tronco linguístico e compõem um grupo isolado da família Tupi. Eles não operam como força unilateral, dado estarem dispersos em comunidades multilocalizadas. A existência da etnia em terras amazônicas se deu por migrações de Tupinambá (ALVAREZ, 2009), sendo o Baixo Amazonas, local onde estão dispersas cerca de 12 mil pessoas sateré-mawé, ponto comum dos nativos dessa etnia residentes a leste do Estado do Amazonas, divisa com o oeste do Pará, compreendendo regiões da Terra Indígena Andirá-Marau (SIASI, 2010).

Os Sateré-Mawé, também moradores em menor quantidade da TI Coatá-Laranjal, a norte de Manaus, já receberam outros nomes na história, dentre eles: Maoos, Mabué, Mangués, Manguês, Jaquezes, Mahués, Magués, Mauris, Mawés, Maraguá, Mahué e Magueses. No entanto, se autodenominam Sateré-Mawé.

Rodrigues (1985), citado por Pereira da Silva (2007), classificou a língua sateré-mawé como pertencente ao Guarani-Tupinambá. O vocabulário mawé é contemplado por elementos estranhos ao Tupi, mas que não podem ser relacionados a outra família linguística. Desde o século XVIII, o repertório esteve sendo reformulado segundo palavras da língua geral: os homens hoje são bilíngues, falando sateré-mawé e português, e parte das mulheres só fala a língua sateré-mawé (PEREIRA DA SILVA, 2007).

Supõe-se que o intercâmbio linguístico dos Sateré-Mawé com demais povos urbanos e mesmo etnias do entorno tende a fomentar imbricadas relações entre língua e cultura, o que orienta a constituição 
RODRIGUES, RIBEIRO NETO e FERREIRA DA SILVA-Saberes indígenas e ressignificação...

social dos índios partindo-se de interseções com a língua de outrem. De maneira que o uso da língua materna, nesse sentido, ao constituir-se enquanto aspecto representativo do saber tradicional dos Sateré-Mawé, reconforma-se quando da incorporação de dialetos ou expressividades linguísticas regionais via aproximação com a sociedade não índia (FRANCESCHINI, 1999; PEREIRA DA SILVA, 2005).

Há possibilidades para a representação de mudanças em traços étnicos do povo a partir da língua e segundo aspectos comunicacionais, dada a proficiência do falante nativo ser via direta para a transmissão de conhecimento e influenciar em modos de ser a partir de constituições de poder e posição social. A problemática, sem ser ponto pacífico na literatura (RODRIGUES e DIETRICH, 1997; PEREIRA, 2003), é ponderada desde quando se percebeu um conjunto de prefixos e numerais que funcionavam como adjetivações para referências a coisas de valor na estrutura familiar dos Sateré-Mawé, com características de estratégia de linguagem para a inserção em camadas parentais estratificadas e não acessíveis a todos, como lideranças xamânicas (GRAHAM, GRAHAM e HARRISON, 1984).

Laraia (1986) e Alvarez (2004), ao estudarem relações interétnicas e processos de diferenciação resultantes da interação dos Sateré-Mawé com o mundo dos brancos, projetaram que o sistema de coesão da etnia, assim como de grande parte dos grupos Tupi, molda decisões em consensos construídos via consulta a chefes familiares. Assim, o fazer político tende a ser transpassado por relações de parentesco e por vezes opções de compadrio.

Similar a essa construção de esquema parental é a motivação para a sociopolítica dos Sateré-Mawé, a qual está resguardada na responsabilidade da pessoa indígena no contexto do comportamento coletivo (BERNAL, 2009). Os aldeamentos, ao possuírem tuxaua investido de autoridade para resolver conflitos internos, convocar reuniões, marcar festas e rituais, orientar atividades agrícolas e atos comerciais, são a representação funcional do destacado (VIVEIROS DE CASTRO, 1995).

Também sobre relações endoétnicas e interétnicas, trabalhos pioneiros ensaiaram descrições sobre o sistema de comunalidade sateré-mawé (NIMUENDAJú, 1948; NUNES PEREIRA, 1967 e 2003), 
RODRIGUES, RIBEIRO NETO e FERREIRA DA SILVA-Saberes indígenas e ressignificação...

compilando informações reunidas no Handbook of South American Indians. Atualmente, relatos sobre igual temática indicam que existe complexidade na descendência patrilinear da etnia, cujo impacto infere a propulsão de casamentos de primos consanguíneos bilaterais, de tios de primeiro grau e de tios com sobrinhas de primeiro grau, sendo estas filhas de sua irmã (ALVAREZ, 2011 ).

A perspectiva infere no contexto do exocasamento da pessoa sateré-mawé, cuja afirmação é controversa dadas as circunstâncias em que a formação consanguínea de clã para clã nem sempre é bem-vinda (HOEBEL e FROST, 2006). No que se remete à temática da autoridade do tuxaua, a ele cabe hospedar visitantes por generosidade ou favor, visando recíproca semelhante no futuro, proceder à função cerimonial de oferecer çapó - bebida de guaraná, tradicionalmente utilizada pelos Sateré-Mawé (TEIXEIRA, 2005) - e, ainda, firmar o preceito coletivo para além dos limites da aldeia, segundo seu desempenho como chefe, suas relações com demais tuxaua e, sobretudo, com o tuxaua-geral da tribo.

O grau de influência política de um tuxaua oscila segundo i) clã a que pertence, ii) relação de parentesco e prestígio junto aos demais tuxaua, iii) conhecimento sobre o tempo dos velhos para história e mitologia, iv) capacidade como orador, v) grau de generosidade, vi) tradição de agricultor e beneficiador de guaraná, vii) habilidade para comércio, viii) resolução de problemas da comunidade e xix) relações com agentes da sociedade envolvente, principalmente Fundação Nacional do Índio (Funai) e políticos locais (WEIGEL e BECKER, 2011).

O poder delegado ou a estrutura do poder entre os Sateré-Mawé tem, porém, suas controvérsias. Não é a organização em clãs e o tuxaua representante do clã que exercem autoridade sobre entes. "[...] Afora os clãs, têm grupos de parentesco, de residência, áreas presididas por comunidade, igrejas, diferentes formas de associação e de organização, vinculações políticas internas e externas etc." (BERNAL, 2009, p. 90). Lideranças compõem junto ao tuxaua a estrutura de poder: i) o capitão, instituído pelo extinto Serviço de Proteção Indígena (SPI) e reforçado pela Funai; ii) o agente indígena de saúde; e iii) o enfermeiro ou técnico de enfermagem do posto local.

$\mathrm{Na}$ esfera social, as relações de casamento, mutualidade e divisão do trabalho obedecem a regras da exogamia clânica. Sem 
RODRIGUES, RIBEIRO NETO e FERREIRA DA SILVA-Saberes indígenas e ressignificação...

rigidez, porém, pois índios podem casar com pessoas do mesmo clã, mas se recomenda a preferência a integrantes de outros clãs, tendo em vista fortalecimentos familiares. A proibição é quanto ao incesto, o qual se limita à relação de consanguinidade entre irmãos e irmãs, filhos de mesmo pai biológico e com parentela simbólica de padrinhos (TEIXEIRA, 2005; ALVAREZ, 2011 ; BARROSO, 2011 ; WEIGEL e BECKER, 2011 ).

O parentesco sateré-mawé estabelece, ainda, o pertencimento político ao grupo. Alvarez (2009, p. 61) aponta que, "assim como outros grupos tupis, os Sateré-Mawé são patrilineares a ponto de não considerar parentes aqueles vinculados pela linhagem materna". Atualmente, clãs passaram a ser "unidades de filiação flexíveis no que concerne ao reconhecimento genealógico, razão pela qual adotam-se membros vindos de fora" (BERNAL, 2009, p. 89).

O ordenamento da labuta entre os Sateré-Mawé não difere significativamente de demais sociedades indígenas em geral: é divido por sexo. Cabem a homens e mulheres atividades separadas, mas trabalhos de plantio e colheita são feitos em puxirum5. A divisão varia em proporção:

[...] os homens se encarregam da caça, da derrubada preparatória para novas roças e da feitura de instrumentos de caça; mulheres plantam, cuidam da roça, colhem alimentos, coletam produtos silvestres, cozinham e buscam água (RAMOS, 2001, p. 31).

$\mathrm{Na}$ economia se destacam agricultura e artesanato. O sentido da produção naturalmente é diferente ante sociedades urbanas e capitalistas, por ser voltada à comunidade acima de demais contextos. A economia indígena é significada a partir da necessidade humana presente, dado que o trabalhador não se aparta de papeis e obrigações comunais para planejar-se individualmente. Ele é chamado a verificar se a produção alcança a totalidade de pessoas que dela dependem. No cultivo, são consideradas questões de ordem social, ritual e religiosa.

Crê-se que inexiste isolamento da pessoa indígena em campos da vida e da subjetividade a partir do trabalho. Infere-se que processos

\footnotetext{
${ }^{5}$ Segundo Bernal (2009, p. 89), puxirum "trata-se de uma espécie de institucionalização dos trabalhos coletivos organizados na ocasião de diversas tarefas agrícolas ou da construção de casas (em particular dos tetos). As famílias mais distantes podem fazer intercâmbio através desse mecanismo".
}

Espaço Ameríndio, Porto Alegre, v. 8, n. 2, p. 206-229, jul./dez. 2014. 
RODRIGUES, RIBEIRO NETO e FERREIRA DA SILVA-Saberes indígenas e ressignificação...

de alienação funcional na sociedade sateré-mawé, como ocorre em sociedades de mercado, tendem a ser minoritários. Se produção não se associa à exploração, indígenas são propensos a serem guiados por planos de reciprocidade e coletivismo.

Importante subproduto da economia sateré-mawé é o guaraná (Paullinia sorbilis). Além de inserir-se no consumo familiar, a planta é comercializada em média escala a partir de produção artesanal oriunda das terras indígenas Andirá-Marau, Coatá-Laranjal e de áreas rurais cultiváveis não nativas do Baixo Amazonas. Os Sateré-Mawé são detentores da sociocultura do guaraná. Eles encontraram meios de cultivar a trepadeira silvestre, somando a domesticação da planta ao beneficiamento (WEIGEL e BECKER, 2011).

O guaraná, cujo consumo se dá no cotidiano e em rituais (çapó e waymat), guarda importância do ponto de vista alimentar e enquanto símbolo de protuberância étnica (TEIXEIRA, 2005). Chamado pelos Sateré-Mawé de waraná, perpassa a tradição e é tomado como bebida agregadora. Alvarez (2009) usa o termo "símbolo raiz" para mostrar que o guaraná é um ícone pleno de significado e dá sentido a diversas esferas - como origem, cosmologia e organização parental - presentes na cultura sateré-mawé.

Destarte o tradicionalismo, a relação de comercialização do produto tem sido permeada por conflitos no interior de comunidades no Baixo Amazonas.

Para os Sateré-Mawé, no plano mítico o significado do waraná nos remete à história de Uniawasap, uma das figuras míticas femininas do grupo. Essa história passase no tempo em que os bichos eram como gente. Conta - mito que Uniawasap morava com seus irmãos no Nozoquem, a terra sem males. Ela era uma moça bonita e detentora do conhecimento mágico sobre plantas. Um dia foi engravidada por uma cobra. Os irmãos, temendo que Uniawasap fosse morar com a cobra, decidiram matar a criança. Uniawasap enterra a criança e de seu corpo brotam diferentes tipos de animais, o guaraná e o povo Sateré-Mawé. Quando enterra o corpo, Uniawasap abençoa o seu filho morto falando que ele voltará e presidirá reuniões (ALVAREZ, 2009, p. 144). 
RODRIGUES, RIBEIRO NETO e FERREIRA DA SILVA-Saberes indígenas e ressignificação...

O mito do guaraná pretende explicar o surgimento dos SateréMawé e a forma de organização grupal da etnia. O guaraná é a plantaentidade que postula coisas do mundo, sendo ela o filho de uniawasap, entidade magnânima que cria regras e faz as coisas acontecerem. $\mathrm{O}$ guaraná dá sentido a relações de poder tradicionais, mitos e alegorias presentes e esquecidas (FIGUEROA, 1997).

O guaraná é fonte mítica cotidiana e o preparo e consumo do çapó (guaraná ralado com água e bebido em cuia) segue uma série de práticas de sessão ritual. A natureza do ritual de consumo do guaraná é, porém, diversa da de rituais formais, como na Festa da Tucandeira (waymat) ou na leitura do Porantim. No waymat, atividade espiritualística de incorporação, a pessoa sateré-mawé ascende a nível de ação interativa, onde o afeto primordial que deverá liberar o corpo dos infantes de forma afetiva/psicossocial para a vida adulta é vinculado a um aceno da autoridade inferida dos tuxaua.

São eles que coordenam e orientam a dança, a colocação de luvas e a cerimônia de dança dentro da oca ou barracão. O simbolismo agregado, de teor afetivo/psicossocial, remete tanto o jovem saterémawé quanto a família dele a iconicidades referentes à procriação e deveres com a seguridade dos entes da comunidade. $\mathrm{O}$ ácido fórmico da tucandeira ${ }^{6}$ imprime o encerramento da tutela dos pais, mas sem que a energia vital do parentesco e da família indígena cesse. Ao estar apto à caça e coleta, guerra e intempéries da vida em geral, o indígena reforma o estado mental para um patamar diferenciado.

$\mathrm{O}$ ato de beber çapó acompanha o waymat. Na medida em que a cerimônia avança se fixam interligados fazeres ritualísticos tanto para neófitos quanto para iniciados, cabendo à mulher do anfitrião ralar o guaraná. A operação é feita com pedra ou língua seca e pirarucu. Uma cuia é colocada em cima de um suporte, o patauí, e enchida de água até um quarto do seu volume total (LORENZ, 1992). Antes trabalha-se o guaraná para que se torne consistente e pastoso.

A viscosidade adere ao ralo e ao pedaço do bastão em uso, sendo dissolvida n'água mediante a periódica submersão dos dedos da

\footnotetext{
${ }^{6}$ Formiga da espécie Paraponera clavata que chega a medir pelo menos $2,5 \mathrm{~cm}$. Sua ferroada pode durar até 24 horas, podendo provocar náuseas, vômitos, dor no estômago, inchaço na área onde ela deixa o ferrão e vermelhidão nos olhos.
}

Espaço Ameríndio, Porto Alegre, v. 8, n. 2, p. 206-229, jul./dez. 2014. 
RODRIGUES, RIBEIRO NETO e FERREIRA DA SILVA-Saberes indígenas e ressignificação...

raladora. Enquanto parte da massa de guaraná descansa, a cuia circula, durante este intervalo, entre as pessoas presentes. Todos bebem da mistura. A mulher do anfitrião, após o ato grupal, continua a esfregar o bastão de guaraná contra o ralo, juntando a pasta que será prontamente dissolvida n'água assim que a cuia voltar às suas mãos (LORENZ, 1992).

Çapó é bebida usada pela mulher sateré-mawé durante os resguardos. Elas, em períodos de menstruação, gravidez, pós-parto e luto, e os homens na Festa da Tucandeira, no luto e quando acompanham suas mulheres durante o resguardo do pós-parto, bebem a mistura. É um marcador étnico concretizado no processo dialético de regeneração corporal. Ao ser utilizado ritualiza e se legitima via transmissão de tradição no seio da comunidade.

Silva ressalta que

o ritual permite a experiência e, nela, a transformação e, ainda, a ação [...] Conhecimento e ação são movimentos constantes, processos que se acumulam e desenvolvem, seguindo o correr do tempo: reafirmações, ajustes, transformações, inovações (SILVA apud SANTANA, 2009, p. 91).

\subsection{Incorporação de outrem ao cotidiano e mítica identitária}

O complexo ritualístico dos Sateré-Mawé, ao assinalar movimento constante de territorialização e desterritorialização de indivíduos, serviu no passado para marcar a integração de migrantes não indígenas à etnia - como no caso de retirantes nordestinos que, após saírem de suas terras incentivados pelo Estado dentro da proeminência de ocupação da Amazônia a partir da década de 1940, foram acolhidos por indígenas em meio a provações orientadas no waymat.

Ademais, durante a migração mais efetiva de nordestinos à Amazônia, em idos das décadas de 1930/40/50, famílias foram territorializadas em meio a ambientes aldeados de Sateré-Mawé, em proximidades da TI Andirá-Marau, ou mesmo na área urbana de Parintins. A atividade de acolhimento a migrantes gerou proeminências familiares em meio a indígenas. Grupos de migrantes se destacaram no 
RODRIGUES, RIBEIRO NETO e FERREIRA DA SILVA-Saberes indígenas e ressignificação...

convívio com nativos.

O clã dos cearenses - ou grupo dos cearenses, na opinião de famílias sateré atualmente estabelecidas na cidade de Parintins (c.f. Sr. Lúcio Sateré, morador da periferia Baixa do São José, sede parintinense) - teve notoriedade na medida em que foram incorporados migrantes do Estado do Ceará em geral a ideários nativos, sendo que o agrupamento foi avolumado nas comunidades de Ponta Alegre e Molongotuba, a sul de Parintins, já adentrando na TI Andirá-Marau.

Esse exemplo de processo de troca fomentado pela migração gerou ganhos na agricultura familiar e coletiva entre indígenas, pois, além do guaraná, passaram a ter eficácia roças de mandioca nas aldeias. A farinha e o peixe, historicamente formadores da base da alimentação indígena, foram acrescidas com os microcultivos.

Quanto ao artesanato - um dos elementos constitutivos da identidade sateré-mawé - a influência estendeu-se aos teçumes, confecções feitas por homens, os quais são, por exemplo, peneiras, cestos etc.; já o teor nordestino percebido em padrões de trabalho das mulheres sateré-mawé é o uso de sementes em colares, brincos e pulseiras, com miçangas diversas em cores esfuziantes.

O conhecimento sobre a confecção de peças artesanais é prática que atravessa gerações. Os Sateré-Mawé tiveram o saber apropriado por artesãos não indígenas e apropriaram-se em diversas medidas de construções culturais dos migrantes, o que acarreta, hoje, em disputa por espaços no atual mercado local, mesmo que incipiente. Aliás, o ato de se apropriar de conhecimento de populações tradicionais tem sido gerador de conflitos desde sempre, uma vez que

[...] podem estar relacionados com apropriação
indevida, com o uso culturalmente inaceitável e
eticamente condenável dos conhecimentos originários e
mesmo com as diferentes formas de desrespeito ao
outro, por meio de ações colonizadoras eivadas de não
reconhecimento à alteridade e frequentemente
carregadas de racismo, intolerância e preconceito
(FREITAS PINTO, 2011, p. 185).

No que se refere ao aspecto mítico, os Sateré-Mawé possuem marcadores étnicos fundamentais de identidade. O guaraná é um deles. Entre outros, cita-se o porantim, bastão sagrado em forma de remo, de 
RODRIGUES, RIBEIRO NETO e FERREIRA DA SILVA-Saberes indígenas e ressignificação...

madeira escura e lisa, com incisões de cor branca. Enquanto símbolo icônico sagrado que insinua tradições orais imemoriais, o porantim é objeto consultivo do legislador social e os Sateré-Mawé se referem a ele como sendo pedra filosofal da etnia.

O porantim carrega poderes de entidades mágicas, funcionando como totem mediúnico para a previsão de acontecimentos. Sua materialidade funcional indica caminhos para apartar desavenças e conflitos. O ícone é suporte onde estão gravados, de um lado, o mito da origem e a história do guaraná; de outro, histórias de guerras. "Posiciona-se para a sociedade que o talhou como instituição máxima, aglutinando esferas política, jurídica, mágico-religiosa e mítica" (LORENZ, 1992, p. 15).

O registrador identitário, como objeto de materialidade, tem ingerência sobre práticas xamânicas por ser elemento que permeia e constitui a coletividade dos Sateré-Mawé, sobretudo em atividades voltadas à etnomedicina. Rodrigues (2014) aborda o papel dessas ingerências em processo de cura ou tratamento em função do porantim. Segundo ele, a

prática xamânica tende a remediar forças da natureza. Entre Sateré-Mawé e Hixkaryana tem se tornado imprescindível a participação de xamãs no tratamento de doenças. Entre outras etnias, a condição parece similar (RODRIGUES, 2014, p. 104).

Figueroa (1997) procura definir a mitologia dos Sateré-Mawé, via objetividade do porantim, enquanto atividade cognitiva com métodos e instrumentos próprios, significada a partir de aportes cosmogônicos e espiritualísticos contextualizados mediante realidade observada e reminiscências. Trabalhos de Cardoso de Oliveira (1964), Esteva Fabregat (1984) e Eriksen (1991) apontam caminhos semelhantes, ressaltando que o discurso mítico tem impacto pró-ativo junto aos indígenas a partir da representatividade do porantim.

Esse remo sagrado invoca êxtases xamânicos que propiciam contato com universos sensíveis e meta-sensíveis mediante instrumentações mentais que captam conhecimentos tradicionais (CARNEIRO DA CUNHA, 2012). Dentro desse conjunto de invocações, não só a materialidade do porantim, mas também a luva usada no ritual 
RODRIGUES, RIBEIRO NETO e FERREIRA DA SILVA-Saberes indígenas e ressignificação...

da Tucandeira é marca étnica identitária que expressa crença de base espiritual. São objetos que simbolizam ritos de passagem dos SateréMawé e tendem a ser descritos por narrativas que os exaltam liricamente como materialidade que fomentam o trabalho, o amor e a chamam vitórias em batalhas (NUNES PEREIRA, 2003).

As luvas utilizadas durante o ritual são tecidas em palha pintada com jenipapo e adornadas com penas de arara e gavião; nelas, o iniciado enfia a mão para ser ferroado por quatro dezenas de formigas tucandeiras (Paraponera clavata $s p$ ). Os Sateré-Mawé ordenam, com isso, a etapa da entrada na maturidade para os homens. O momento é coletivo e ativa redes sociais no ambiente local e intercomunitário. $\mathrm{O}$ waymat expressa concepções de passagem da vida de criança à adulta, sendo estímulo para se forjar guerreiros, maridos e homens de família (PEREIRA DA SILVA, 2007).

O indígena da etnia, para ser considerado guerreiro saterémawé, passa pelo waymat ao menos 20 vezes na vida. Diferentemente da sociedade ocidental, divisora das fases do ser humano em criança, adolescente, jovem e adulta em idade cronológica, sociedades indígenas em geral, e especialmente a sateré-mawé, dividem em duas fases: criança e adulta. O que define o adulto é o fato dele estar pronto para caçar, pescar e organizar plantios.

No contexto feminino, o ritual da Menina Moça é traço da cultura sateré-mawé que marca a transição de criança ao status de pessoa adulta, aprontando-a para o casamento e para ser mãe. Dá-se na época da primeira menstruação, cujo período é marcado por estados mentais e corporais de reclusão e tabu alimentar, que acompanham mudanças de status e transformação da menina em mulher para a procriação e responsabilidades produtivas na aldeia (BARROSO, 2011).

O Menina Moça caracteriza-se pela constituição de um status de pessoa cuja delimitação forma-se em face à orientação para a procriação e a manutenção da unidade da família étnica. $O$ ordenamento ritualístico ocorre findas as regras iniciais da menarca e define o ato de ter relevante posição social sobre quem ainda não ascendeu em sua faixa etária à situação de emancipação do corpo (BARROSO, 2011).

Sobre a prática e suas complexidades, não nos deteremos neste artigo. Cabe, porém, sublinhar que o objetivo da observação sobre o 
RODRIGUES, RIBEIRO NETO e FERREIRA DA SILVA-Saberes indígenas e ressignificação...

Menina Moça foi situar a existência de um contraponto à masculinidade do waymat. Contraponto, inclusive, que objetiva o empoderamento sobre o próprio corpo e nesse aspecto o ato é um processo civilizador dentro do contexto sateré-mawé, pois, para os pais da indígena que participa do Menina Moça, após a cerimônia, o desejo sexual da mulher deixa de ser um imperativo intolerável para ser apreciado e incentivado.

No mais, sem detrimento às breves linhas referentes ao ritual da Menina Moça e considerando a problemática tratada neste tópico, tendeu-se a apresentar a possibilidade de acesso à cosmologia da etnia segundo aspectos da sagração dentro da constituição de herança indígena. Herança porque diz respeito ao conhecimento transmitido de geração a geração e que configura a identidade étnica.

\subsection{Identidade frente a reconformação de saberes tradicionais}

A constituição identitária dos Sateré-Mawé perpassa por processos de rupturas e continuidades. Experiências vivenciadas por essas populações tradicionais são fatores determinantes, sendo que a afirmação étnica ou a perda dela depende do grau de transmissão de conhecimentos de velhos para jovens e de influências externas em espaços urbanos.

O conceito de identidade, conforme Hall (2006), é amparado no âmbito da identidade cultural. Essa perspectiva é fundada a partir de "aspectos de nossas identidades que surgem do pertencimento a culturas étnicas, raciais, linguísticas, religiosas e, acima de tudo, nacionais" (HALL, 2006, p. 9).

Entre os Sateré-Mawé, o sentimento de pertencimento é latente em razão do fortalecimento de grupos e clãs que marcam suas autoafirmações por padrões de comportamento e saberes compartilhados. Todavia, controvérsias relacionadas à intersecção aldeia-cidade em diversos sentidos geram implicações psicossociais. Não se trata de considerar desvalorizações do saber tradicional em função da aproximação com outras formas de conhecimento. O que se projeta são déficits de engajamento ou de reconformação da identidade étnica a partir de modos de vida em sociedades de consumo (CESARINO, 
RODRIGUES, RIBEIRO NETO e FERREIRA DA SILVA-Saberes indígenas e ressignificação...

2008).

Os Sateré-Mawé carregam consigo quatro marcadores fundamentais de identidade que podem flutuar face à complexidade da vida urbana: i) consumo ritual e consumo cotidiano de guaraná, ii) funções do tuxaua, iii) funções da materialidade no artesanato e iv) ritos de iniciação masculina e feminina. Estes apresentam-se imbricados psicossocialmente na reconformação da pessoa a partir da vida na urbe. Dentre os elementos da mudança, está a exigência de mercado inserida no contexto das propriedades socioculturais dos itens referidos, objetivada em relações interétnicas, tanto nacionais quanto globais, com implicações na produção de guaraná - selo cultural da etnia.

Exemplo do sublinhado é o projeto Waraná7. A partir dele, relações mercantis têm concorrido para redefinições da política indígena. A mudança ocorre em bases nas quais a parceria comercial acrescenta efeitos opostos ao desejado inicialmente. São novas necessidades posicionais construídas e que tendem a estabelecer ambiguidades fomentadoras de tensões e interferências. Esse reposicionamento se dá por causa da política étnica ser pautada em uma cosmopolítica, diferente da prática não indígena.

O projeto é intermediado pela empresa local Sapoema Ltda. (Sociedade dos Povos para o Eco-desenvolvimento da Amazônia), que une o capital social de três sujeitos jurídicos: o Conselho Geral da Tribo Saterê Mawé (CGTSM); a Cooperativa Agrofrut, de Urucará; e a Agrorisa (Produtos Alimentícios Naturais Ltda), em Manaus. A Associação de Consultoria e Pesquisa Indigenista da Amazônia (Acopiama) é uma ONG que presta assessoria nas negociações. As empresas globais são: Guaiapy Tropical, da França; a CTM Altromercato, da Itália; e a Gepa (the Fair Trade Company), pertencente ao Europe Fair Trade Association (EFTA); além das ONGs italianas ACRA, ECEEC e Cooperativa Chico Mendes, com sedes em Modena, Itália.

O Waraná, desta feita, apesar de ser ancorado na concepção de comércio justo, apresenta-se controverso ao defender autossuficiência econômica e empoderamento da etnia sem trabalhar no sentido de

\footnotetext{
${ }^{7}$ O projeto Waraná iniciou em 1995, quando o Conselho Geral das Tribos Saterê-Mawé (CGTSM) se articulou com apoio de ONGs italianas, como a ACRA e o ECEEC, bem como da Cooperativa Chico Mendes. O objetivo era dar segurança político-econômica ao território sateré-mawé via recuperação de cultivos e do manejo do guaraná nativo com mudas locais.
}

Espaço Ameríndio, Porto Alegre, v. 8, n. 2, p. 206-229, jul./dez. 2014. 
RODRIGUES, RIBEIRO NETO e FERREIRA DA SILVA-Saberes indígenas e ressignificação...

amenizar a emergência de conflitos na organização interna dos indígenas. Membros do Conselho Geral da Tribo dos Sateré-Mawé e do Consórcio de Produtores dos Índios Sateré-Mawé, inseridos no complexo dessa comercialização, buscam atualmente autonomia econômica para granjearem autonomia política, invertendo a cosmovisão tradicional, o que tem gerado dissabores e entraves interpessoais.

A entrada de intermediadores na compra do guaraná, baseada em associações para gestão da produção, alavancou conflitos internos em anos recentes. Distinção disso foi o que o CGTSM denunciou sobre a empresa francesa Guaiapy Tropical. Segundo a entidade, ocorreu desvio de recursos da venda do guaraná, bem como houve a publicação sobre mitos sateré-mawé sem a autorização de líderes indígenas. A suposição foi notificada pelo presidente da Coordenação das Organizações Indígenas da Amazônia Brasileira (COIAB), Jecinaldo Barbosa, exmembro do CGTSM, em uma disputa de poder em torno da questão do comércio justo.

Com base na polêmica, estimam-se os questionamentos: i) em que medida se estabelece a organização política indígena tendo como pressupostos democracia e racionalidade quando relações não se baseiam em processos de impessoalidade?; ii) até que ponto clãs, famílias, xamãs e lideranças políticas conseguem se comunicar em termos igualitários com empresários e representantes comerciais estrangeiros?; e iii) de que maneira podem ser formadas organizações indígenas e empresariais de caráter impessoal?

Parte da resposta advém das relações de troca, lógica de capital e das relações de tradição, as quais são reguladas diferentemente em ambientes tradicionais e urbanos. A objetividade e a impessoalidade dos negócios e do capital firmam-se como conceitualização polêmica à pessoa étnica, enquanto que a orientação simbólica e a afetividade de territórios e parentescos fazem pouco sentido no universo branco, empresarial. A relação do sistema de prestação de favores e trocas, seja ela baseada em clãs, parentescos, compadrios ou prestação de serviços ou obrigações - o que Mauss (2011) denominou de sistema de prestações totais -, não raro tem entrado em conflito com a lógica comercial que se pretendeu estabelecer via projeto Waraná. 
RODRIGUES, RIBEIRO NETO e FERREIRA DA SILVA-Saberes indígenas e ressignificação...

A tentativa de ordenamento e organização da produção do comércio de guaraná encontrou atores sociais dispostos a mediar o trâmite do mercado ante os tradicionais, ensaiando abrandamentos para conflitos advindos da prática, mas interpondo polêmicas contemporâneas. Na contramão desse aceno, relações de poder e padrões de comportamento irmanados da comercialização concretizamse, de encontro ao equilíbrio proposto pela ideia de comércio justo e tendendo a fazer flutuar desregramentos de poderes imemoriais e imateriais de tuxaua, caciques e xamãs.

Outrossim, a consolidação da atividade econômica com esteio no fair trade pode conter contradições aparentes dado o desafio de investir em produção comercial denominada de não capitalista dentro do capitalismo e a partir de um mercado de exportação. Ademais, práticas próprias ao associativismo terão ou não possibilidade de conter dimensões éticas que relacionem a economia ao sistema cosmopolítico dos Sateré-Mawé, seja para o volume da produção ou para a qualidade dela, o que seria contraditório ante a perspectiva do comércio justo, onde necessariamente as localidades se sobrepõem a questões produtivistas.

\section{Considerações finais}

Considerou-se que conhecimentos sobre natureza, cosmogonia, crença mítica e ritual são elementos peculiares a populações indígenas. Entre índios Sateré-Mawé, saberes historicamente transmitidos por oralidade incorporam expressões icônicas e elementos que possibilitam aperfeiçoamentos e ressignificações coletivas.

Inferiu-se que a etnia, ao dominar a cultura do guaraná, elemento vivo de sua constituição identitária, tende a se manter afirmativa em face da importância do item para o autorreconhecimento. No caso, o ritual da Tucandeira é um elemento étnico afirmador, e modificações ocorridas nesses marcadores seriam perceptíveis dado seu caráter manifesto, uma vez que essa planta é afeto essencial.

Compreendeu-se que práticas simbólicas, embora naturalmente modificadas, ao constituírem a identidade sateré-mawé, possuem 
RODRIGUES, RIBEIRO NETO e FERREIRA DA SILVA-Saberes indígenas e ressignificação...

gerência na transmissão de conhecimentos em termos globais. Atualmente, porém, com a infusão das negociações no campo do projeto Waraná, há tendência a jovens e adultos desvalorizarem narrativas ancestrais. Mudanças estruturais no cotidiano, porém, não desqualificam a mítica da etnia. O que ocorre são reorganizações no contato com a sociedade ocidental.

No trânsito de saberes, espera-se dialogia entre sociedade urbana e indígena, fortalecendo trocas interculturais e fomentando incrementos multiétnicos, sobretudo por conta de que, embora se perceba ganhos econômicos nos últimos anos, a participação coletiva da comunidade sateré-mawé ante questões simbólicas e territoriais tem diminuído, o que impacta todo um conjunto de crenças, valores e ideologia indígenas.

\section{Referências bibliográficas}

ALVAREZ, Gabriel O. Política Sateré-Mawé: do movimento social à política local. Revista de Estudos e Pesquisas, Brasília, v. 1, n. 2, p. 9-44, dez. 2004. 2009.

Satereria: Tradição e Política Sateré-Mawé. Manaus: Valer/CAPES/PRODOC,

Pós-Dradiviano Sateré-Mawé: parentesco y rituales de afinabiliadad. Vibrant, Brasília, v. $8, \quad$ n. 2 , p. 373-402, 2011. Disponível em: http://www.vibrant.org.br/issues/v8n2/gabriel-o-alvarez-pos-dradiviano-satere-mawe/. Acesso em: 28 dez. 2014.

ARGUELLO, Carlos. Etnoconhecimento na escola indígena. Natal, 2001. (Palestra proferida na sociedade brasileira de Física).

BARROSO, Milena Fernandes. Rotas Críticas das Mulheres Sateré-Mawé no enfrentamento da violência doméstica: novos marcadores de gênero no contexto indígena. 2011. 140 f. Dissertação (Mestrado em Serviço Social e Sustentabilidade na Amazônia) - Universidade Federal do Amazonas, [2011].

BERNAL, Roberto Jaramillo. Índios Urbanos: processo de reconformação das identidades étnicas indígenas em Manaus. Manaus: Faculdade Federal do Amazonas/Faculdade Salesiana Dom Bosco, 2009.

CARDOSO DE OLIVEIRA, Roberto. O índio no mundo dos brancos: a situação dos 
RODRIGUES, RIBEIRO NETO e FERREIRA DA SILVA-Saberes indígenas e ressignificação...

Tukúna do Alto Solimões. São Paulo: Difusão Europeia do Livro, 1964.

CARNEIRO DA CUNHA, Manuela. Questões suscitadas pelo conhecimento tradicional. Revista de Antropologia, São Paulo, v. 55, n. 1, p. 439-464, 2012.

CESARINO, Pedro de Niemeyer. Babel da floresta, cidades dos brancos?: Os Marubo no trânsito entre dois mundos. Novos Estudos/CEBRAP, São Paulo, n. 82, p. 133-148, 2008.

COHN, Clarice. Culturas em transformação: os índios e a civilização. São Paulo Perspec., São Paulo, v. 15, n. 2, p. 36-42, 2001. Disponível em: http://www.scielo.br/scielo.php?script=sci_arttext\&pid=S010288392001000200006\&lng= en\&nrm=iso. Acesso em: 01 nov. 2014.

DIEGUES, Antônio Carlos. O mito moderno da natureza intocada. São Paulo: HUCITEC/NAPAUB/USP, 2008.

DIEGUES, Antônio Carlos, PEREIRA, Bárbara Elisa. Conhecimento de populações tradicionais como possibilidade de conservação da natureza: uma reflexão sobre a perspectiva da etnoconservação. Desenvolvimento e Meio Ambiente, Curitiba, n. 22, p. 37-50, jul./dez. 2010.

ESTEVA FABREGAT, Claudio. Estado, etnicidad y biculturalismo. Barcelona: Ediciones Península, 1984.

ERIKSEN, Thomas. The cultural contexts of ethnic differences. Man, Oslo, v. 26, n. 1, p. 127-144, 1991.

FERREIRA, Luciane Ouriques. Jurupari ou "visagens": reflexões sobre os descompassos interpretativos existentes entre os pontos de vista psiquiátrico e indígenas. Mediações, Londrina, v. 16, n. 2, p. 249-265, jul./dez. 2011.

FIGUEROA, Alba Lucy Giraldo. Guerriers de l'Ecriture et Commercants du Monde Enchanté: Histoire, Identite et Traitement du Mal chez les Satere-Mawe (Amazonie Centrale, Bresil). 1997. Tese (Doutorado em Antropologia) - Ecole des Hautes Etudes en Sciences Sociales, [1997].

FRANCESCHINI, Dulce. La Langue Sateré-Mawé: Description et analyse morphosintaxique. 1999. $321 \mathrm{f}$. Tese (Doutorado em Linguística) - Université Paris VII (Denis Diderot), [1999].

FREITAS PINTO, Renan. Etnoconhecimento e Etnociência. In: CATTANI, David Antônio (Org.). Dicionário de trabalho e tecnologia. Porto Alegre: Zouk, 2011. p. 184-191.

GRAHAM, Albert; GRAHAM, Sue; HARRISON, Carl. Prefixos pessoais e numerais da língua Sateré-Mawé. Série Lingüística, Brasília, n. 11, p. 175-206, 1984. 
RODRIGUES, RIBEIRO NETO e FERREIRA DA SILVA-Saberes indígenas e ressignificação...

HALL, Stuart. A identidade cultural na pós-modernidade. São Paulo: DP\&A, 2006.

HOEBEL, Adamson; FROST, Everett. Antropologia cultural e social. São Paulo: Cultrix, 2006.

LARAIA, Roque de Barros. Tupi: índios do Brasil atual. São Paulo: FFLCH/USP, 1986.

LORENZ, Sônia da Silva. Sateré Mawé: os filhos do guaraná. São Paulo: Centro de Trabalho Indigenista. 1992.

MAUSS, Marcel. Sociologia e Antropologia. São Paulo: Cosac \& Naify, 2011.

NIMUENDAJÚ, Curt. The Maue and Arapium. In: STEWARD, Julien (Org.). The tropical forest tribes. Washington: Smithsonian Institution Bureau of American Ethnology, 1948. p. 245-254. v. 3.

NUNES PEREIRA, Manuel. Moronguêtá: um decameron indígena. Rio de Janeiro: Civilização Brasileira, 1967.

2003.

Os Índios Maués. Manaus: Editora Valer/Governo do Estado do Amazonas,

OLIVEIRA, Almir de. As malocas indígenas do Alto Rio Negro: saberes e patrimônio cultural. In: BRAGA, Sérgio Ivan Gil (Org.). Cultura Popular, Patrimônio Imaterial e Cidades. Manaus: Universidade Federal do Amazonas, 2007.

OLIVEIRA, Assis da Costa. Direitos e/ou povos e comunidades tradicionais: noções de classificação em disputa. Desenvolvimento e Meio Ambiente, Curitiba, v. 27, p. 71-85, jan./jun. 2013.

PEREIRA DA SILVA, Raynice Geraldine. Estudo Fonológico da língua SateréMawé. Campinas: Unicamp, 2005.

Esboço sociolinguístico Sateré-Mawé. Tellus, Campo Grande, v. 7, n. 13, p. 73-101, 2007.

RAMOS, Alcida Rita. Sociedades Indígenas. São Paulo: Ática, 2001.

RODRIGUES, Aryon Dall'Igna; DIETRICH, Wolf. On the linguistic relationship between mawé and tupi-guarani, Diachronica, Amsterdam, v. 14, n. 2, p. 265-304, 1997.

RODRIGUES, Renan Albuquerque. Sofrimento mental de indígenas na Amazônia. Manaus: Edua/Ufam, 2014.

SAHLINS, Marshall. 'O pessimismo sentimental' e a experiência etnográfica: porque a cultura não é um 'objeto' em via de extinção (parte I). Mana, Rio de Janeiro, v. 3, n. 1, 
RODRIGUES, RIBEIRO NETO e FERREIRA DA SILVA-Saberes indígenas e ressignificação...

p. 41-73, 1997a.

. 'O pessimismo sentimental' e a experiência etnográfica: porque a cultura não é um 'objeto' em via de extinção (parte II). Mana, Rio de Janeiro, v. 3, n. 2, p. 103-150, $1997 b$.

SANTANA, José Valdir Jesus de. A face simbólica dos "saberes da tradição" e a produção de identidades no contexto do povo indígena Kiriri. Revista Espaço Acadêmico, Maringá, v. 9, n. 101, p. 87-95, 2009.

SILVA, Maria de Lourdes Ferreira da. Índios Urbanos: um estudo acerca do acesso dos Sateré-Mawé residentes na Casa de Trânsito Indígena aos Direitos Sociais no município de Parintins/AM. 2011. 68 f. Monografia (Graduação em Serviço Social) - Universidade Federal do Amazonas, [2011].

TEIXEIRA, Pery (Org.). Sateré-Mawé: retrato de um povo indígena. Manaus: UNICEF, 2005.

VIVEIROS DE CASTRO, Eduardo (Org.). Antropologia do parentesco: estudos ameríndios. Rio de Janeiro: UFRJ, 1995.

O nativo relativo. Mana, Rio de Janeiro, v. 8, n. 1, p. 113-148, 2002. Disponível em: http://www.scielo.br/scielo.php?script=sci_arttext\&pid=S010493132002000100005\&lng=en\&nrm=iso. Acesso em: 01 nov. 2014.

Xamanismo transversal: Lévi-Strauss e a cosmopolítica amazônica. Museu Nacional, Rio de Janeiro. 2007. (Palestra proferida em outubro de 2007, no departamento de antropologia da Universidade de Cambridge).

WEIGEL, Valéria A. C. M.; BECKER, Maria Alice D’Ávila. Educação, meio ambiente e saúde na vida Sateré-Mawé: uma análise bioecológica. Ver a Educação, Belém, v. 12, n. 2, p. 299-311, 2011.

Espaço Ameríndio, Porto Alegre, v. 8, n. 2, p. 206-229, jul./dez. 2014. 